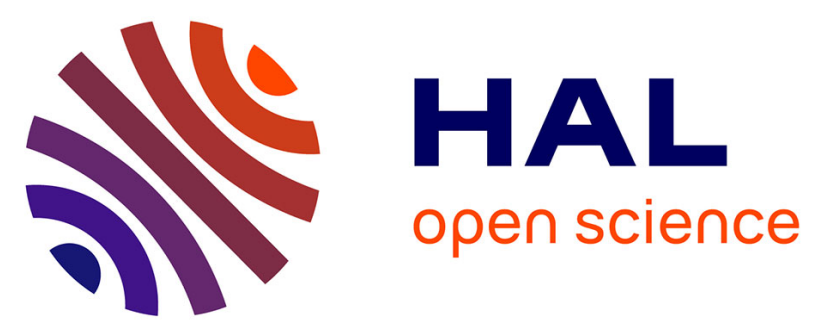

\title{
Overpressure wave interaction with droplets: time resolved measurements by laser shadowscopy
}

Pierre Slangen, Laurent Aprin, Frederic Heymes, Laurent Munier, Emmanuel Lapebie, Gilles Dusserre

\section{- To cite this version:}

Pierre Slangen, Laurent Aprin, Frederic Heymes, Laurent Munier, Emmanuel Lapebie, et al.. Overpressure wave interaction with droplets: time resolved measurements by laser shadowscopy. SPECKLE 2012: V International Conference on Speckle Metrology, Sep 2012, Vigo, Spain. pp.841312, 10.1117/12.978639 . hal-02012043

\section{HAL Id: hal-02012043 \\ https://hal.science/hal-02012043}

Submitted on 3 Jun 2021

HAL is a multi-disciplinary open access archive for the deposit and dissemination of scientific research documents, whether they are published or not. The documents may come from teaching and research institutions in France or abroad, or from public or private research centers.
L'archive ouverte pluridisciplinaire HAL, est destinée au dépôt et à la diffusion de documents scientifiques de niveau recherche, publiés ou non, émanant des établissements d'enseignement et de recherche français ou étrangers, des laboratoires publics ou privés. 


\title{
Overpressure wave interaction with droplets: Time resolved measurements by laser shadowscopy
}

\author{
Pierre Slangen $^{* a}$, Laurent Aprin ${ }^{\mathrm{a}}$, Frédéric Heymes ${ }^{\mathrm{a}}$, Laurent Munier ${ }^{\mathrm{b}}$, Emmanuel Lapébie $^{\mathrm{b}}$, Gilles Dusserre ${ }^{\mathrm{a}}$ \\ ${ }^{a}$ Ecole des Mines d'Alès, LGEI, ISR, 6 Avenue de Clavières, 30319 Ales Cedex, France; \\ ${ }^{\mathrm{b}}$ CEA Gramat, BP80200, 46500 GRAMAT
}

\begin{abstract}
Risk sciences involve increasingly optics applications to perform accurate analysis of critical behavior such as failures, explosions, fires. In this particular context, different area sizes are investigated under high temporal sampling rate up to $10000 \mathrm{fps}$. With the improvement of light sources and optical sensors, it is now possible to cope with high spatial resolution even for time resolved measurement. The paper deals with the study of the interaction between overpressure waves, occurring in case of explosion for example, with a liquid droplet present in the vicinity of the overpressure wave. This is a typical scenario encountered in case of industrial breakdown including liquid leakage and explosions. We designed an experimental setup for the evaluation of the interaction between the overpressure wave and falling liquid droplets. A gas chamber is filled with nitrogen until breakage of the outlet rupture disk at about 4 bar. The droplets fall is controlled by an automatic syringe injector placed in the overpressure wave. The imaging system is based on laser shadowscopy. The laser source is a double cavity $15 \mathrm{~mJ}-1000 \mathrm{~Hz} \mathrm{Nd}$ YLF laser emitting double pulses of about $10 \mathrm{~ns}$ at $527 \mathrm{~nm}$. To record the double pulse after crossing the falling droplets, the transmitted light is captured by a lasersynchronized double frame camera. Since these measurements are time-synchronized, it is then possible to know accurately the different parameters of the phenomenon, such as overpressure wave velocity, droplets diameter, and Reynolds number. Different experiments have been carried out at about 4000 doubleframe/s. The paper presents the whole experiment, the enhancements of the setup and the results for different liquid products from water to acetone.
\end{abstract}

Keywords: TRPIV, image correlation, atomization, droplets, free fall, jellyfish

\section{INTRODUCTION}

In industrial accidents involving successive explosions, it is likely to have flying fragments, shock waves and high heat radiation. Debris impacting a tank of low flammable product in conventional storage conditions can result in most cases in the loss of containment of the product. This release is commonly ejected in the surrounding atmosphere in the form of big liquid droplets or filament [1]. As mentioned by Krishna [2], these droplets have an important probability to disperse over a significantly larger area than the bulk liquid. In addition, the interaction of this two phase jet with a shock wave, coming from another explosion, may fragment these big droplets into aerosol. This aerosol may achieve conditions of inflammation or explosion. Febo \& Valiulis [3] report that certain flammable liquids below their flash points may become flammable or explosive after atomization.

Figure 1 shows the interaction between a shock wave coming from an explosion and a liquid jet. All the operating conditions are the same that those detailed in the study of Lecysyn [4]. The test was performed with a $60 \mathrm{~L}$ tank filled with water and $40 \%$ of Poly Ethylene Glycol. A spherical projectile (diameter $13 \mathrm{~mm}$, mass $20 \mathrm{~g}$ ) is launched toward the tank at a velocity up to $1000 \mathrm{~m} . \mathrm{s}^{-1}$. Figure 1a shows the formation of the liquid jet after impact. Figure $1 \mathrm{~b}$ shows the ignition of the explosive with an increase of the ambient light due to the fireball from the explosion. Figure 1c represents the interaction between the shock wave and droplets. Fragmentation of liquid generates high atomisation and the apparition of white bright cloud generating problems to measure droplets diameters. To better understand these fragmentation mechanisms it was decided to investigate this point, especially atomisation at droplet scale. 


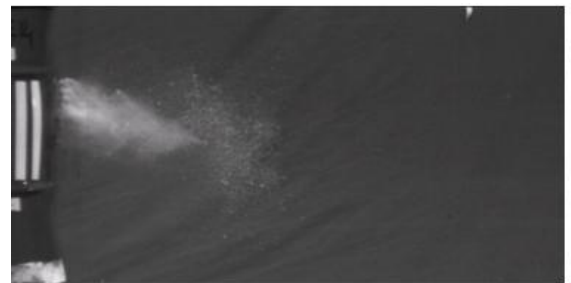

a) liquid jet before explosion $\left(T_{0}\right)$

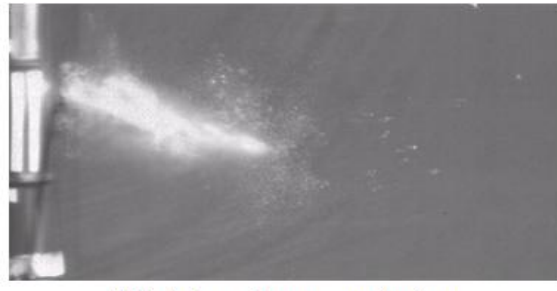

b) lighting due to explosion $\left(T_{0}+5.610^{-3} \mathrm{~s}\right)$

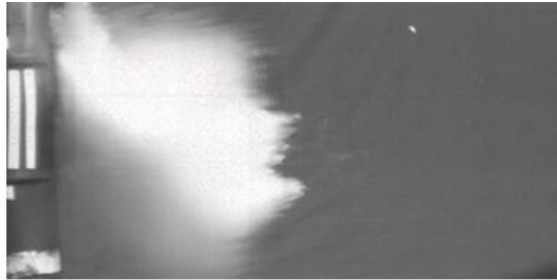

c) fragmentation due to shock wave $\left(\mathrm{T}_{0}+710^{-3} \mathrm{~s}\right)$

Figure 1: Visualization of interaction between liquid jet shock wave generated by explosion

Phenomena of atomization of falling droplets by air flow have been investigated by many researchers [5]. The process of disintegration is mainly influenced by the difference between the air flow velocity and the droplet velocity. Moreover, aerodynamic forces and the development of instabilities at the liquid-gas interface play an important role in the breakup of droplets. Others parameters such as density and viscosity of both fluids, acceleration of the liquid drop are important variables of this disintegration. As mentioned by Hirahara [6], the Weber number plays an important role on atomization description:

with $\rho_{g}$ is the air density, $\sigma$ the surface tension of the liquid, $u_{g}$ the velocity of the air flow and $D_{0}$ the initial diameter of droplet before disintegration. Figure 2 presents three different regimes of droplet breakup versus Weber number proposed by Lee [7].

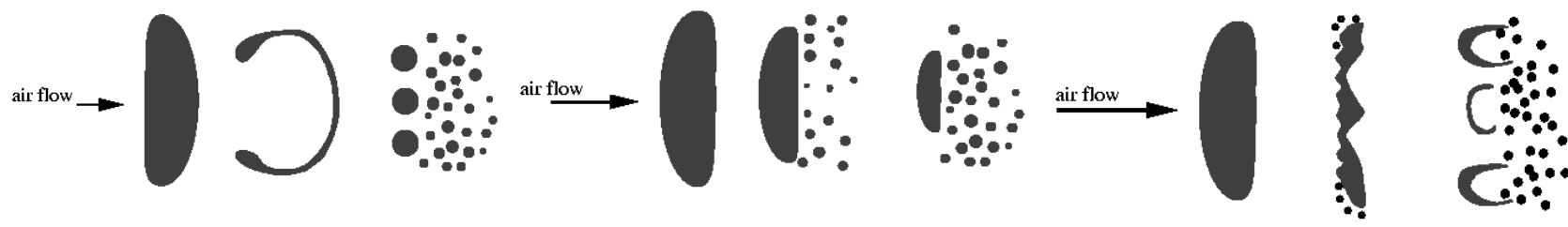

$\begin{array}{ll}\text { (a) Bag breakup: } 12<\mathrm{We}<80 & \text { (b) Stripping breakup: } 80<W e<350\end{array}$

(c) Catastrophic breakup: $\mathrm{We}>350$

Figure 2: Schematic representation of droplet breakup mechanisms [7]

The present study investigated the influence of fluid physical properties (viscosity and surface tension) on the breakup mode with two fluids: water and acetone. To observe these phenomena, shadowgraphy analysis is performed with a laser as light source and a double frame high speed camera

\section{EXPERIMENTAL SET-UP}

\subsection{Test section description}

The experimental arrangement used in this study is shown schematically in Figure 3. A horizontal cylindrical steel pressurized vessel with an inside diameter of 6 inches was used to generate the overpressure wave. Pressure and temperature inside the vessel were measured respectively with dynamic and static pressure sensors and $\mathrm{K}$ thermocouples. Nitrogen was employed as filling gas to pressurize the vessel and a soft metallic thin sheet was used as rupture disc. The rupture pressure of the disc was about 4 bar. Falling droplets were generated with a needle connected to an automatic syringe injector device. Two fluids were tested for this study, water and acetone. Density, viscosity and surface tension of the fluids are reported in table 1.

The pressurized vessel was located on a separated bench. This bench can easily roll on aluminum guides to vary the distance between the overpressure wave generator and the droplet without changing the optical configuration. 
Table 1 : Physical properties for water and acetone used in this study

\begin{tabular}{|c|c|c|}
\hline & water & acetone \\
\hline Density $\left[\mathrm{kg} \cdot \mathrm{m}^{-3}\right]$ at $20^{\circ} \mathrm{C}$ and $1 \mathrm{bar}$ & 1000 & 783 \\
Dynamic viscosity $[\mathrm{Pa} . \mathrm{s}]$ at $20^{\circ} \mathrm{C}$ and $1 \mathrm{bar}$ & $1.001610^{-3}$ & $3.210^{-4}$ \\
Surface tension $\left[\mathrm{N} \cdot \mathrm{m}^{-1}\right]$ at $20^{\circ} \mathrm{C}$ and $1 \mathrm{bar}$ & $7310^{-3}$ & $23.710^{-3}$ \\
\hline
\end{tabular}

The measurement section was located at $0.9 \mathrm{~m}$ in front of the rupture disc. Two different overpressure measurements were performed simultaneously. Firstly, the shape of the overpressure was evaluated with three dynamic pressure sensors at same distance from the rupture disk (Figure 3). Secondly, a device designed specifically with three aligned pressure sensors (P1, P2, P3) permitted to measure the overpressure velocity. The sensors were located with an offset of $5 \mathrm{~cm}$. The acquisition rate was $60 \mathrm{kHz}$.

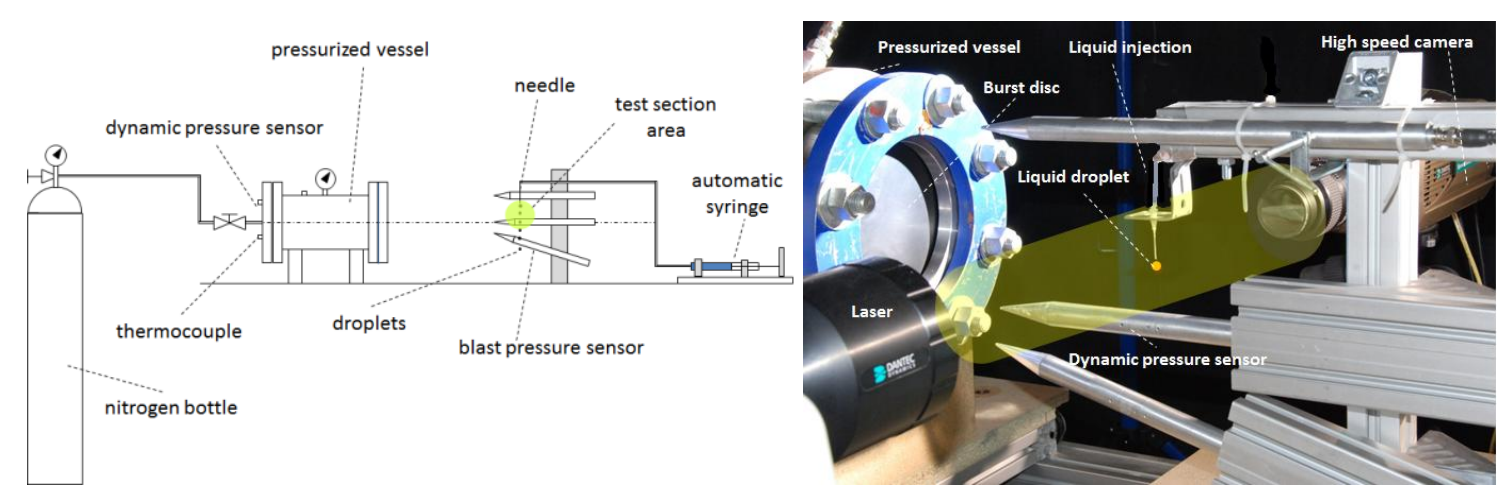

Figure 3: Experimental configuration

\section{$2.2 \quad$ Optical set-up}

Two different systems were designed: double pulse laser source and double frame camera, and continuous white light source with high speed single frame camera. Both have been turned to shadowscopy [8] to focus on the drops and to detect and measure the overpressure wave, respectively. Both systems were triggered at the rupture disc break.

\subsubsection{Droplet characterization}

The optical setup was mainly composed with a double pulsed laser synchronized with a high speed double frame camera $(1280 * 800$ pixels, $1000 \mathrm{~Hz})$ as shown in Figure 3. All the components were synchronized through a timer box driven by DynamicsStudio (Dantec Dynamics, Denmark). Different tests were performed to get the best compromise between temporal and spatial resolutions. The nominal parameters are given at $1000 \mathrm{~Hz}$ for the double cavity common path frequency-doubled Nd-YLF laser delivering $15 \mathrm{~mJ} 10 \mathrm{~ns}$ double pulses with interpulse time from $\mu$ s to $\mathrm{ms}$ at $527 \mathrm{~nm}$. The laser head was equipped with a light source enlarger to decrease the spatial coherence of the laser beam. This was reached by impinging the direct laser beam on fluorescent diffuser placed at the object plane of the exit Fresnel lens system. It was then possible to adjust the beam diameter up to 2 inches wide when collimated and also to focus or defocus it. Liquid optical fiber can also be used in other configurations to deliver the beam up to 2 or 5 meters away.

The Phantom double frame camera recorded up to 1000 double fr/s for $1280 * 800$ pixels. The laser and the camera were synchronized to cope with the "Q-switch to light" delay. The camera acquisition was configured in rolling buffer memory. The size of the rolling buffer was about 5463 double-frames. The system also offered the possibility to stream the image recording on SATA hard disk up to 1To of images. As the overpressure wave effect is rather fast, resolution has been decreased down to $640 * 480$ pixels to reach 4228 double fr/s with $8 \mu$ s of time between double frames. For $640 * 480$ image and $18.5 \mu \mathrm{m} /$ pixel magnification, the region of interest (ROI) was about $12 \mathrm{~mm}$ by $9 \mathrm{~mm}$. This is given from the optical objective with $105 \mathrm{~mm}$ of focal length equipped with $2 \mathrm{X}$ conversion lens. The aperture was then reduced from 2.8 to 5.6 but without affecting the sensitivity of the camera as the laser power is greatly sufficient to work in the 
best dynamic range of the optical sensor for such ROI. Focus was sharply done on the falling droplets. Therefore line profiles through drops images were performed to reach the best contrast ensuring the correct focus. The depth of focus was about some millimeters but covered the whole diameter of the larger drops which is around $1.5 \mathrm{~mm}$.

\subsubsection{Overpressure wave characterization}

This setup was placed nearby the TR shadowscopy setup. The light source was a single superluminescent white LED placed at the focal plane of the collimating lens. The light tube was then perturbed by the overpressure wave and the objective of the camera was focused a bit in front of the overpressure wave axis to ensure the correct sensitivity to the overpressure wave on the optical path of light.

The high speed single frame camera, Photron model SA3-120K, enables to grab full resolution (1024x1024 pixels) images at $2 \mathrm{kfr} / \mathrm{s}$. Camera acquisition was configured in rolling buffer memory. The images where then downloaded to disk and can be saved in 16 bits tiff images. This configuration was really convenient as it is possible to choose the switch bit and so to optimize the grayscale dynamic to lower or higher bits when converting to 8 bits.

To sample the overpressure wave propagation and to cope with its velocity, the SA3 camera was operating at $15 \mathrm{kfps}$ with reduced resolution (256x256 pixels). Exposure time was $1 / 500000$ s to freeze the overpressure wave and ensures the desired frequency acquisition. Typical images are presented Figure 3 showing the good dynamic of the images with the 18000lumen superlum diode as presented in the literature by Hargather et al. [9], [10]. As the ROI is not large, superlum diode is as much efficient and low cost regarding common 500W Xenon light. As discussed by Hargather et al., it is even possible to get nice shadowgraphs for wide areas when using in-line Edgerton's photography. We will not discuss such applications in the present paper but we successfully applied in-line Edgerton's photography to marine pollution detection in the water column. We also call this set-up Pure In-Line Shadowgraphy (PILS) to easily use this acronym among PIV (Particle Image Velocimetry), PLIF (Planar Laser Induced Fluorescence) and many others.

\section{RESULTS}

\subsection{Released gas characteristics}

The rupture of the membrane entailed two phenomena: the release of the compressed gas and the dynamic overpressure peak. Image processing of the typical shadowgraphs presented at Figure 4. The two phenomena can be observed. Gas release appears on the (b) picture whereas the overpressure can be noticed on the (c) picture. The main advantage of the optical measurement is the possibility to measure the shape and the speed of both phenomena in the same time.

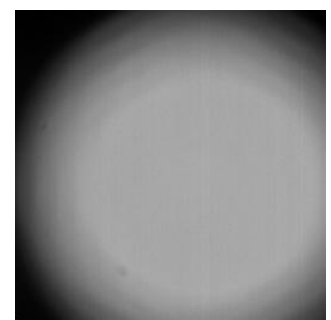

(a)

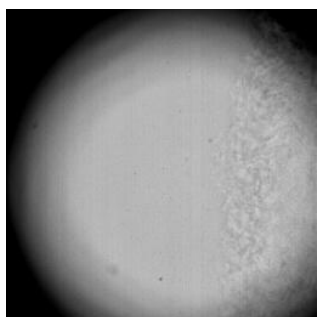

(b)

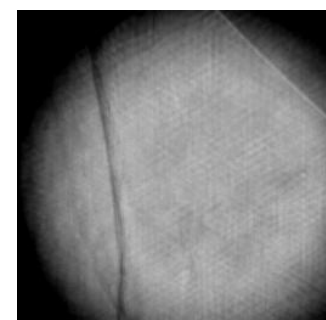

(c)

Figure 4: Examples of overpressure wave effect: Before rupture (a), first loss (b) and overpressure wave $(\mathrm{c})\left(\Delta \mathrm{t}_{\mathrm{cb}}=867 \mu \mathrm{s}\right)$

Figure 5 represents the overpressure variation recorded by the pressure transducers versus time for water and acetone tests. It can be noticed that this overpressure is almost the same for water and acetone tests with values in a range of 1420 mbar. The difference between P1 and P3 is probably due to the inclination of P3 pressure gauge which may involve some perturbations and measurement fluctuations on the sensor. Each sensor spaced of $5 \mathrm{~cm}$ from the drop combined with the measured gap between the three sensors allowed to evaluate the variation of the overpressure wave velocity. Analysis of these measurements shows a slight decrease in speed between sensors P1 and P3. The results show that the average velocity of the gas at the falling droplet is almost $40 \mathrm{~m} \cdot \mathrm{s}^{-1}$. 


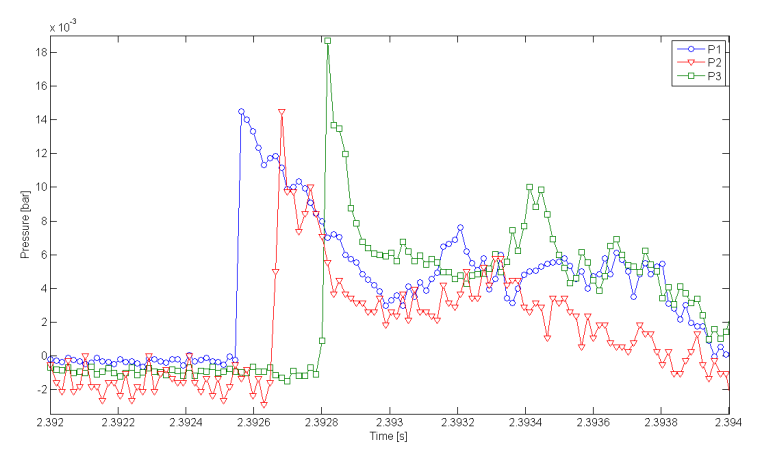

(a) Water

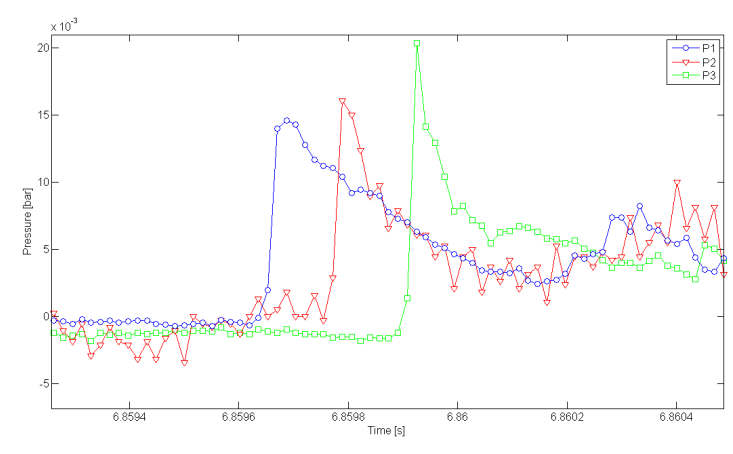

(b) acetone

Figure 5: Variation of overpressure pressure $v s$ time in the area of falling droplet: (a) water test, (b) acetone test

\subsection{Time Resolved Shadowgraphy}

Different products for droplet formation and distances of interaction were tested. Water and acetone results are solely presented in this paper with the same distance of interaction for reasons of simplicity and concision.

Moreover the best way to show TR measurement is to produce slow motion movie and so some characteristic pictures extracted from the double frame high speed movies are presented in this paper.

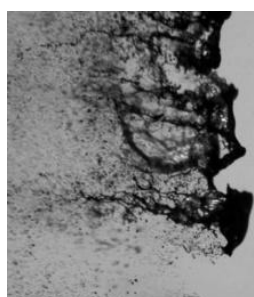

(a)

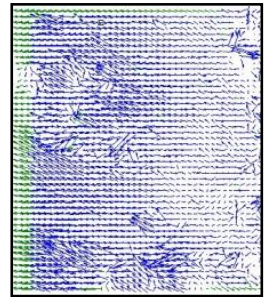

(b)

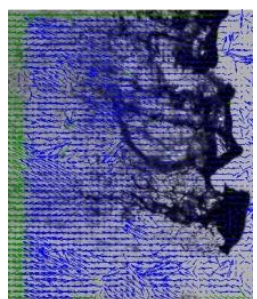

(c)

Figure 6: PIV measurements on acetone drops: Atomization (a), Velocity vectors (b) Overlay results (c)

DynamicsStudio software enables to control the recording parameters and also to analyze the final movies with robust particle tracking and particle image velocimetry (DIC) intuitive routines. Shadow tracking and shadow sizing give the shape and velocity of the falling droplets before their interaction with the overpressure wave and until there is strong atomization or liquid clusters generation. To characterize the flow of clusters or of atomized droplets, PIV with adaptative correlation window is performed to get the velocity fields. The software must take into account the fact that images are separated by two different times: time between two pulses or time between two double frame rates. PIV velocity fields are presented in Figure 6.

Both products have been analyzed with the same parameters of correlation routines. Even if the same range of velocity (between 10 and $80 \mathrm{~m} / \mathrm{s}$ ) is achieved for both products (Figure 6), the distributions of the speed are rather different as the geometrical interactions are completely contrasting.

Different behaviors are presented with typical breaking shapes like stripping, bag breakup or jellyfish (Figure 7). Water presents both effects before atomization while acetone passes through lens and saucer shape (stripping) instead of bag breakup before making jellyfish and atomization. Considering drops of $1.5 \mathrm{~mm}$ of diameter, and the mean speed at $40 \mathrm{~m} / \mathrm{s}$ yields to We 40 for water and We 124 for acetone. Compared to [6] and [7], these data lead to bag breakup for water and stripping for acetone, which is confirmed by the geometric behavior of the droplets as shown on Figure 7. 


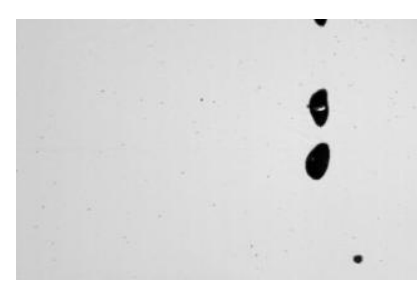

(a) acetone drops

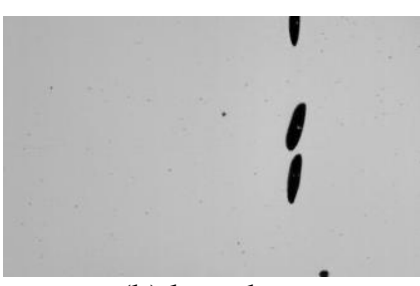

(b) lens shape

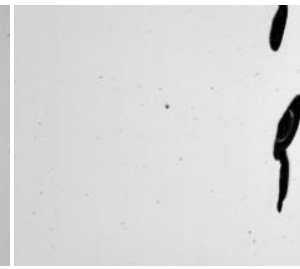

(c) saucer shape

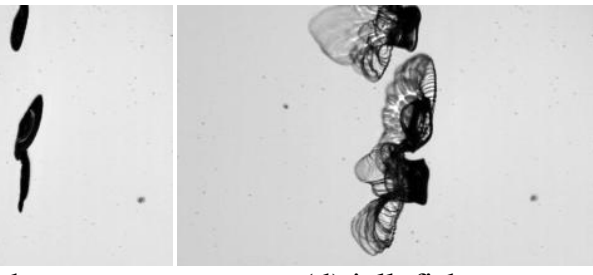

(d) jellyfish

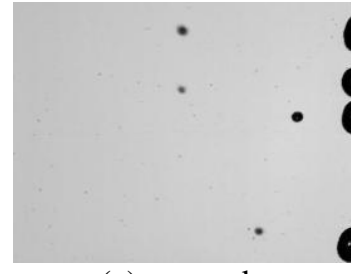

(e) water drops

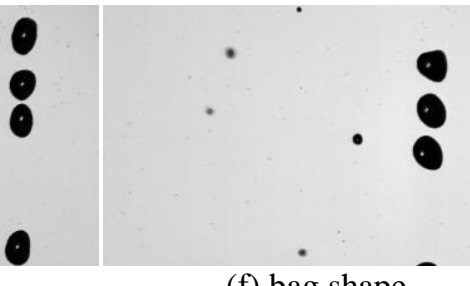

(f) bag shape

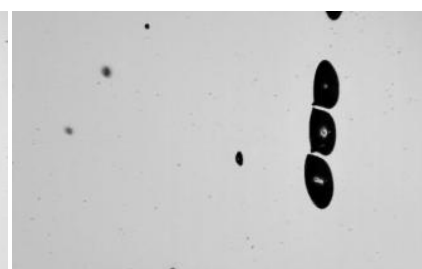

(g) bag breakup

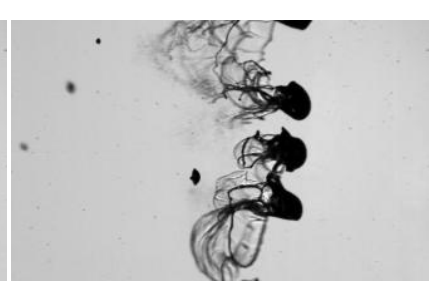

(h) jellyfish

Figure 7: Geometric behavior of interaction with overpressure wave for acetone and water free falling droplets

\section{CONCLUSION}

This study focuses on the fragmentation of water or acetone droplets impacted by an overpressure wave. The developed experimental setup enables to determine the pressure variations of the overpressure wave nearby the falling drops. Timeresolved shadowscopy was used to measure the drop velocities before and after impact and also to show the different fragmentation regimes for water and acetone. These results are in very good agreement with Lee $e t$ al and also enable to know the different characteristics of the drop fragmentation. These characteristics (e.g. size and velocities) suggest fluids like acetone could lead to explosive regime if highly fragmented during an accident occurring on industrial site.

\section{REFERENCES}

[1] Lecysyn, N., Dandrieux, A., Heymes, F., Aprin, L., Slangen, P., Munier, L., Le Gallic, C., Dusserre, G., "Ballistic impact on an industrial tank: Study and modeling of consequences", J. Hazard. Mat., .172(2-3), 30 December 2009, 587-594 (2009).

[2] Krishna, K., Rogers, W.J., Mannan, M.S.,"The use of aerosol formation, flammability, and explosion information for heat-transfer fluid selection", J. Hazard. Mat., Volume 104, Issues 1-3, 14 November 2003, 215-226 (2003).

[3] Febo, H.L., Valiulis, J.V., "Heat transfer fluid mist explosion potential an important consideration for users", Proc. AIChE Loss Prevention Symposium, Norwood, Main, Factory Mutual Research Corporation, (1995).

[4] Lecysyn, N., Dandrieux, A., Heymes, F., Slangen, P., Munier, L., Lapebie, E., Le Gallic, C., Dusserre, G., "Preliminary study of ballistic impact on an industrial tank: Projectile velocity decay", J. of Loss Prev. Process Ind., Volume 21, Issue 6 November, 627-634 (2008).

[5] Pilch, M., Erdman, C.A., "Use of breakup time data and velocity history data to predict the maximum size of stable fragments for acceleration-induced breakup of a liquid drop", Int. J. Multiphase Flow 13 (6) (1987) 741757.

[6] Hirahara, H., Kawahashi, M., "Experimental investigation of viscous effects upon a breakup of droplets in highspeed air flow", Exp. Fluids 13, 423-428 (1992).

[7] Lee, C.H., Reitz, R. D., "An experimental study of the effect of gas density on the distortion and breakup mechanism of drops in high speed gas stream", Int. J. of Multiphase Flow, Volume 26, Issue 2, 229-244 February (2000).

[8] Settles, G. S. [Schlieren and Shadowgraph Techniques: Visualizing Phenomena in Transparent Media], Springer-Verlag, Berlin, (2001).

[9] Hargather, M. J., Lawson, M. J., Settles, G. S., Weinstein, L. M., Gogineni, S., "Focusing-Schlieren PIV Measurements of a Supersonic Turbulent Boundary Layer", Proc. 47th AIAA Aerospace Sciences Meeting, 5 8 January 2009, Orlando, Florida, AIAA 2009-69 (2009).

[10] Hargather, M. J., Settles, G. S., "Retroreflective shadowgraph technique for large-scale flow visualization", Appl. Opt., 48(22), August (2009). 